Review

\title{
Inhibitory learning approaches to exposure therapy: A critical review and translation to obsessive-compulsive disorder
}

\author{
Ryan J. Jacoby *, \&, Jonathan S. Abramowitz \\ University of North Carolina at Chapel Hill, Davie Hall, Campus Box 3270, Chapel Hill, NC 27599, United States
}

\section{H I G H L I G H T S}

- Habituation as an indicator of improvement could have unintended consequences.

- Inhibitory learning theory can be applied to treating OCD and its heterogeneity.

- Introducing "desirable difficulties" into exposure may maximize long-term outcome.

- Research translating inhibitory learning theory to exposure is in its nascent stage.

\section{A R T I C L E I N F O}

\section{Article history:}

Received 17 February 2016

Received in revised form 14 July 2016

Accepted 22 July 2016

Available online 25 July 2016

\section{Keywords:}

Exposure

Therapy

Extinction

Inhibitory learning

Obsessive compulsive disorder

\begin{abstract}
A B S T R A C T
The majority of treatment research on OCD has focused on pre/post treatment efficacy of exposure-based interventions, with less attention directed towards (a) understanding mechanisms of change, and (b) maximizing long-term effectiveness. Inhibitory learning theory (ILT) provides a novel foundation for understanding how exposure therapy reduces fear. Moreover, ILT is consistent with empirical evidence that raises questions about the more traditional (i.e., habituation) explanation for exposure therapy's efficacy. Yet ILT has yet to be applied to understanding the treatment of OCD and its heterogeneity. The current review is an examination of human experimental research on ILT that seeks to translate laboratory findings on fear extinction to exposure therapy across empirically established OCD symptom dimensions. We provide an up-to-date critical review of the existing evidence for a series of strategies derived from ILT that have been proposed for the treatment of fear, discuss the limitations of existing studies, and provide suggestions for future research within this rapidly accelerating area of study. We also offer conceptual considerations for applying these principles to the treatment of OCD symptom dimensions. A common theme is the idea of introducing "desirable difficulties" into the implementation of exposure in order to foster more durable long-term learning.
\end{abstract}

(c) 2016 Elsevier Ltd. All rights reserved.

\section{Contents}

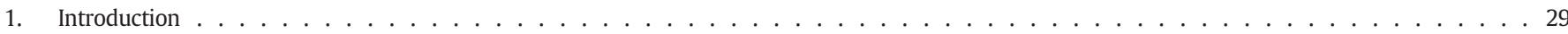

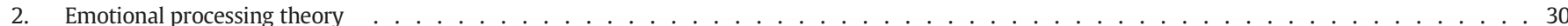

2.1. Is habituation an indicator of learning? . . . . . . . . . . . . . . . . . . . . . . . . . 30

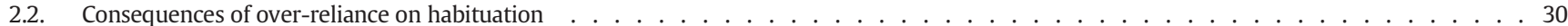

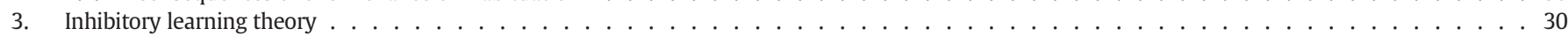

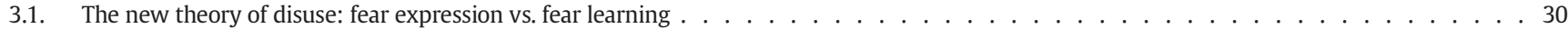

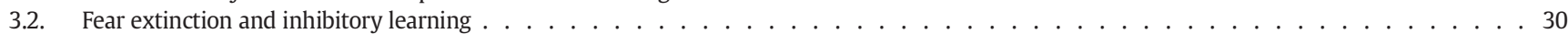

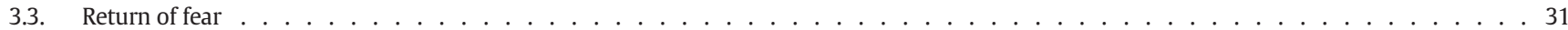

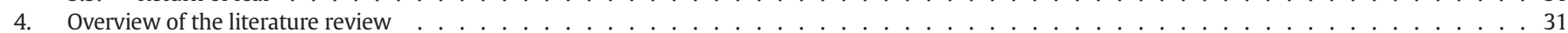

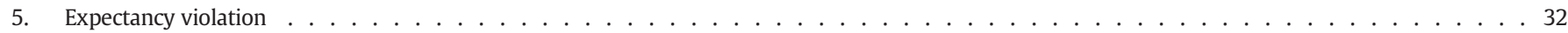

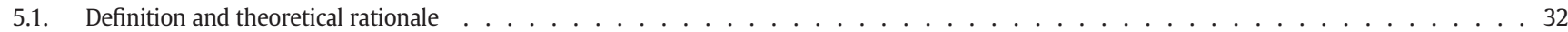

5.2. Clinical applications . . . . . . . . . . . . . . . . . . . . . . . . . . . . . . . . . . . . . . . . . . . . .

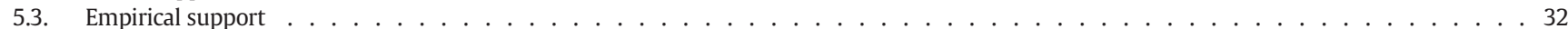

\footnotetext{
* Corresponding author at: Department of Psychology, UNC-Chapel Hill, Davie Hall, Campus Box 3270, Chapel Hill, NC 27599, United States.

E-mail address: rjjacoby@unc.edu (R.J. Jacoby).
} 
5.4. Applications to OCD treatment . . . . . . . . . . . . . . . . . . . . . . . . . . . . . . . . . . . . 32

5.5. Suggestions for future research . . . . . . . . . . . . . . . . . . . . . . . . . . . . . . . . . . . . . . . . 33

6. Combining multiple fear cues . . . . . . . . . . . . . . . . . . . . . . . . . . . . . . . . . . . . . . . . . . . . 33

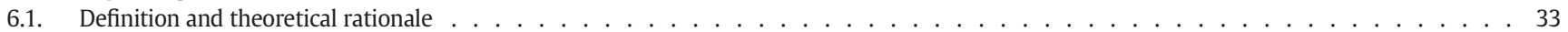

6.2. Clinical applications .. . . . . . . . . . . . . . . . . . . . . . . . . . . . . . . . . . . . . 33

6.3. Empirical support ... . . . . . . . . . . . . . . . . . . . . . . . . . . . . . 34

6.4. Applications to OCD treatment .. . . . . . . . . . . . . . . . . . . . . . . . . . . . . . . . . . . . . 34

6.5. Suggestions for future research . . . . . . . . . . . . . . . . . . . . . . . . . . . . . . . 35

7. Maximizing contextual variability . . . . . . . . . . . . . . . . . . . . . . . . . . . . . . . . . . . . . . . 35

7.1. Definition and theoretical rationale . . . . . . . . . . . . . . . . . . . . . . . . . . . . . . . . . . . . . 35

7.2. Clinical applications . . . . . . . . . . . . . . . . . . . . . . . . . . . . . . . . . . . . . . . 35

7.3. Empirical support . . . . . . . . . . . . . . . . . . . . . . . . . . . . . . . . . . . . . . 35

7.3.1. Exposure stimuli . . . . . . . . . . . . . . . . . . . . . . . . . . . . . . . . . 35

7.3.2. External environment ... . . . . . . . . . . . . . . . . . . . . . . . . . . . . . . . 35

7.3.3. Physiological/interoceptive . . . . . . . . . . . . . . . . . . . . . . . . . . . . . . . . . . . . . 35

7.4. Applications to OCD treatment . . . . . . . . . . . . . . . . . . . . . . . . . . . . . . . . . . . 36

7.5. Suggestions for future research . . . . . . . . . . . . . . . . . . . . . . . . . . . . . . . . . . . . . 36

8. Expanding the inter-session interval . . . . . . . . . . . . . . . . . . . . . . . . . . . . . . . . . . . . . . . . . . 36

8.1. Definition and theoretical rationale . . . . . . . . . . . . . . . . . . . . . . . . . . . . . . . . 36

8.2. Clinical applications . . . . . . . . . . . . . . . . . . . . . . . . . . . . . . . . . . . . . . . . . . . . . . . . 37

8.3. Empirical support . . . . . . . . . . . . . . . . . . . . . . . . . . . . . 37

8.4. Applications to OCD treatment . . . . . . . . . . . . . . . . . . . . . . . . . . . . . . . . . . . . . . . 37

8.5. Suggestions for future research . . . . . . . . . . . . . . . . . . . . . . . . . . . . . . . . 37

9. Conclusions, limitations, and future directions . . . . . . . . . . . . . . . . . . . . . . . . . . . . . . . . . . . . . . . . . . . . . . . . . . . . . . . . .

Acknowledgments . . . . . . . . . . . . . . . . . . . . . . . . . . . . . . . . . . . . . . . . . . . 38

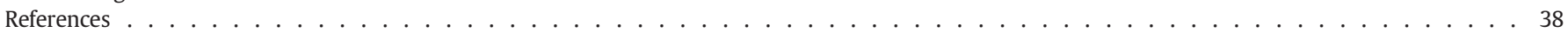

\section{Introduction}

Exposure and response prevention (ERP) is the most efficacious psychological treatment for obsessive-compulsive disorder (OCD; e.g., Olatunji, Davis, Powers, \& Smits, 2012). This intervention involves helping patients confront stimuli that provoke obsessional fear, but that objectively pose a low risk of harm. Exposure can occur in the form of actual encounters with feared situations or stimuli (situational or in vivo exposure), or in the form of imagined confrontation with the feared consequences of engaging with these stimuli (imaginal exposure). For example, an individual with obsessional fears that she unknowingly hit a pedestrian while driving her car would practice driving through crowded streets for situational exposure, and then confront doubts that she hit someone and could be held responsible. The response prevention component of ERP entails refraining from compulsive rituals and other behaviors that serve as an escape from obsessional fear. In the previous example, the patient would resist checking the roadside or the local news for reassurance that no such accidents have occurred.

Randomized controlled studies from around the world (e.g., Foa et al., 2005) indicate that ERP is more effective than credible control interventions (e.g., relaxation, anxiety management, pill placebo), with large pre-post effect sizes (e.g., Hedges's $g=1.39$ in Olatunji et al., 2012), and with a substantial percentage of patients attaining clinically-significant improvement (e.g. 69\% in Eddy, Dutra, Bradley, \& Westen, 2004). Despite these outcomes, a sizeable percentage of patients (14-31\%) are classified as non-responders (Foa et al., 2005; Norberg, Calamari, Cohen, \& Riemann, 2008), and of those who respond, up to $50-60 \%$ experience at least partial relapse at later follow-up assessments (Eisen et al., 2013; Simpson, Franklin, Cheng, Foa, \& Liebowitz, 2005). While some authors (e.g., Whittal, Thordarson, \& McLean, 2005) suggest abandoning ERP altogether on the basis of these statistics (and the perceived "intolerability" of exposure exercises as described in Meyer, Farrell, Kemp, Blakey, \& Deacon, 2014), an alternative approach is to focus efforts on improving the short- and long-term outcomes of this otherwise effective intervention.

In line with this latter option, Craske et al. (2008) have highlighted limitations of the long-standing and widely accepted idea that exposure therapy works by breaking conditioned fear responses via habituation (i.e., Emotional Processing Theory, EPT; e.g., Kozak \& Foa, 1997). In contrast, laboratory research on fear extinction indicates that these associations do not break or disappear; rather exposure therapy leads to the learning of new non-threat (i.e., inhibitory) associations that compete with (rather than "break") older threat associations. An important aim of exposure therapy, therefore, is to promote the encoding and longterm recall of the newly learned non-threat connections so that they will inhibit fear-based learning; a process termed "inhibitory learning".

Research examining various facets and applications of inhibitory learning has accumulated in the last few decades, with some inconsistencies in findings across studies. Since the introduction of this area in 2008 , however, there have been no comprehensive reviews critiquing this body of empirical work. Moreover, the recent experimental and clinical literature testing a priori hypotheses related to the inhibitory learning approach has focused almost exclusively on specific fears (e.g., spiders, heights, public speaking). Yet when the aforementioned room for improvement in ERP outcomes is considered along with the potential of the inhibitory learning approach, one recognizes the promise of translating this approach to the treatment of OCD. The aim of the current paper, therefore, is threefold. First, we highlight the major tenants, advantages, and confines of both the emotional processing and inhibitory learning accounts for how ERP is applied in the treatment of OCD. Second, we present a critical review of the existing human literature addressing implications of inhibitory learning for exposure therapy. While there exists a comprehensive animal literature on extinction learning and return of fear that parallels basic human laboratory research (Milad \& Quirk, 2012; Milad, Rauch, Pitman, \& Quirk, 2006; Phelps, Delgado, Nearing, \& LeDoux, 2004; Quirk \& Mueller, 2008), there have frequently been contradictory findings when comparing animal and human studies (e.g., Thomas \& Ayres, 2004; Vervliet, Vansteenwegen, Hermans, \& Eelen, 2007). Accordingly, this review will reference important research using animal populations, but focus primarily on translational research using human participants. Third, we translate the inhibitory learning literature to the use of ERP for OCD. OCD is a heterogeneous condition requiring adaptation of ERP in various ways. Specifically, research has identified four theme-based symptom dimensions (Abramowitz et al., 2010; McKay et al., 2004), including: (a) contamination obsessions and decontamination rituals, (b) obsessions about being responsible for harm and checking rituals, 
(c) obsessions and rituals related to symmetry, completeness, and the need for things to seem "just right", and (d) unacceptable obsessional thoughts (e.g., concerning violence, sex, or religion) and mental neutralizing rituals. Thus, we address the translation of research on inhibitory learning to the application of ERP for these various OCD presentations.

\section{Emotional processing theory}

Emotional processing theory (EPT; Foa, Huppert, \& Cahill, 2006; Foa \& Kozak, 1986; Foa \& McNally, 1996) has traditionally been the dominant model for explaining improvement during ERP (Abramowitz, Deacon, \& Whiteside, 2011); although see Hyman and Pedrick (2010) for an exception. This theory proposes that therapeutic exposure must activate a "fear structure" that is contained in memory, and then provide information that is incompatible with the fear structure. This incompatible information is thought to become integrated via "corrective learning," such that non-fear based elements replace (Foa \& Kozak, 1986), or compete with (Foa \& McNally, 1996; Foa et al., 2006), fear based associations. Fear reduction during exposure (i.e., habituation, Groves \& Thompson, 1970; Lader \& Mathews, 1968; Watts, 1979) is considered a critical index of change in ERP and evidence that learning is taking place. Habituation is a short-term sensory effect resulting in one's "decreased response to repeated stimulation" (Groves \& Thompson, 1970, pp. 419) such that one's "original reaction towards the stimulus diminishes in intensity or even disappears" (Eelen, Hermans, \& Baeyens, 2001, pp. 251). Thus, patients who experience habituation are expected to respond less fearfully to anxiety-related stimuli over time. Lang (1971) suggests that fear reactions are comprised of three response symptoms: verbal (i.e., self-report quantification of anxiety level using the Subjective Units of Distress scale, SUDS; Wolpe, 1973), behavioral (e.g., observable escape and avoidance behaviors that function to reduce anxiety and fear, such as compulsive rituals), and physiological (e.g., heart rate [HR] and skin conductance [SC]). In the present review, therefore, we also quantify fear reactions along these lines. Foa and colleagues proposed three indicators of emotional processing that predict successful outcomes in exposure therapy: (1) initial fear activation (IFA; peak fear level during an exposure minus baseline fear level before exposure began), (2) within-session habituation (WSH; peak fear level during an exposure minus ending fear level), and (3) between-session habituation (BSH; peak fear level during an exposure minus peak fear level during the subsequent exposure). These authors further suggest that between-session habituation is dependent on within-session habitation, and thus is the basis for longer-term learning.

This focus on habituation has several implications for the delivery of ERP as traditionally described (Foa, Yadin, \& Lichner, 2012). First, when providing the rationale for exposure, therapists are instructed to explain that repeated and prolonged exposure leads to a reduction in anxiety both during the exposure session as well as across sessions. Second, exposure session length is determined by time to habituation (i.e., exposures are terminated when habituation occurs). Third, exposure begins with moderately fear-provoking stimuli and progresses gradually up to more intense stimuli (i.e., up the exposure "hierarchy"). Clinicians are also cautioned that treatment effectiveness is closely linked to habituation (e.g., Foa \& Kozak, 1986).

\subsection{Is habituation an indicator of learning?}

Learning is "the capacity of a living organism to alter its behavior as a result of experience" (Eelen et al., 2001, pp. 250). Exposure therapy is a procedure that is used to facilitate learning because its goal is behavior change (i.e., approach vs. escape/avoidance behavior) as a result of new experiences with previously feared (and avoided) stimuli. Although habituation typically occurs within and between exposure sessions (e.g., Grayson, Foa, \& Steketee, 1982), the literature examining habituation as a predictor of exposure therapy outcome (at post-test and longer-term follow-up) is mixed. Across different fear-based conditions, some studies have found that greater WSH predicts better treatment outcome (Foa et al., 1983; van Minnen \& Hagenaars, 2002), whereas others have found no such relationship (Baker et al., 2010; Jaycox, Foa, \& Morral, 1998; Kozak, Foa, \& Steketee, 1988; Meuret, Seidel, Rosenfield, Hofmann, \& Rosenfield, 2012). Additionally, one study that examined the inter-relationship between WSH and BSH found no significant association (Baker et al., 2010), challenging EPT's tenant that WSH is a necessary prerequisite of BSH. Other studies demonstrate that successful response to exposure can occur in the absence of habituation (e.g., Rachman, Craske, Tallman, \& Solyom, 1986; Rowe \& Craske, 1998b; Tsao \& Craske, 2000). These investigations suggest that habituation is neither a reliable predictor of exposure therapy outcome (short- or long-term) nor tantamount to learning. In other words, there is disconnect between fear expression during learning and fear learning itself (Craske et al., 2008).

\subsection{Consequences of over-reliance on habituation}

Given the aforementioned research, dependence on habituation as an indicator of improvement during ERP could have unintended negative consequences. Emphasizing the importance of fear reduction during ERP, for example, implies that anxiety itself is inherently bad, and that treatment is only successful if one is anxiety-free. This may perpetuate a "fear of fear" mindset and lead patients to interpret inevitable (and normal) unexpected surges of fear (either within or outside of exposure trials) as signs of failure. Individuals with OCD might also use exposures to control their anxiety (i.e., "I know I can do this exposure because my anxiety will come down"), which is contrary to the aim of confronting and learning to tolerate anxiety and fear as normal and nonthreatening experiences (Abramowitz \& Arch, 2014). Although decades of success with exposure from an EPT perspective are well-documented (Abramowitz et al., 2011), the treatment literature speaks primarily to relatively short-term outcomes (in a recent meta-analysis of OCD treatment, $<20 \%$ of studies reported follow-up results; Olatunji et al., 2012). Thus, relatively little is known about the extent to which emphasizing fear reduction attenuates longer-term retention of treatment gains.

\section{Inhibitory learning theory}

\subsection{The new theory of disuse: fear expression vs. fear learning}

Bjork and Bjork (1992)'s New Theory of Disuse proposes that learned associations remain in memory even with "disuse." In other words, once they are learned, such associations don't fade over time; rather access to them does. While generally adaptive, this process can be problematic for those with fear-based problems such as OCD, as the persistence of fear-based associations (even with disuse) leaves them vulnerable to relapse. In applying this theory to exposure therapy, Bjork and Bjork (2006) argued that exposure therapists often incorrectly assume that performance during exposure trials (i.e., habituation) is indicative of long-term learning. Accordingly, clinicians may favor treatment techniques that facilitate performance during the session (e.g., systematic and gradual exposure to foster habituation) versus methods that might maximize the long term encoding and generalization of what has been learned during the exposure session.

\subsection{Fear extinction and inhibitory learning}

Fear extinction is the type of learning that occurs during exposure therapy. Whereas habituation refers to a reduction in fearful responding to repeated presentations of a stimulus during treatment (i.e., non-associative learning), extinction is a form of associative learning in which a person repeatedly confronts fear-eliciting stimuli (i.e., conditioned stimuli; CS) in the absence of an aversive unconditioned stimulus (US), with the desired result being: (a) altered 
expectancies about the likelihood and severity of feared consequences (i.e., one no longer expects the US to follow the CS), and (b) corresponding behavior change (i.e., reduction in conditioned responding; e.g., approach rather than escape/avoidance behavior; Eelen et al., 2001; Milad \& Quirk, 2012; Myers \& Davis, 2007; Vansteenwegen, Dirikx, Hermans, Vervliet, \& Eelen, 2006). Thus, while the two processes are related (indeed previous authors have purported that habituation contributes to the extinction of conditioned responding; McSweeney \& Swindell, 2002), they are not equivalent (Abramowitz et al., 2011).

As an example of extinction learning, consider a patient with OCD with a fear of contracting the herpes virus from touching doorknobs in public restrooms. For this individual, doorknobs have become a conditioned feared stimulus, such that when the patient approaches or touches a doorknob he experiences a conditioned fear response (i.e., intense fear/anxiety, urges to escape). During exposure therapy (i.e., extinction), the patient practices confronting doorknobs without the presence of an aversive outcome (e.g., anxiety did not last as long as was expected and no contraction of herpes occurs) resulting in extinction of conditioned responding. Thus, during this process, the patient learns that doorknobs are not as dangerous as expected.

Inhibitory learning theory (ILT; A. J. Lang, Craske, \& Bjork, 1999; Myers \& Davis, 2007) is a model proposed to explain the process of extinction. According to ILT, the original threat association learned during fear acquisition is not erased or replaced by the new non-threat associations learned during extinction trials (i.e., exposure therapy). Rather, the CS (e.g., doorknob) becomes an ambiguous stimulus with two meanings that both remain in memory and compete for retrieval (e.g., Bouton, 1993; Bouton \& King, 1983; Rescorla, 1996): (a) the original excitatory meaning acquired during fear acquisition (i.e., when a cue is paired with an aversive reinforcer; CS-US), and (b) a new inhibitory meaning acquired during extinction learning (i.e., when the fear-eliciting cue is experienced in the absence of the aversive reinforcer; CS-noUS). The fact that these original fear-based associations remain is demonstrated by the fact that fear can return following successful exposure therapy, which we discuss in the following section.

\subsection{Return of fear}

Return of fear (ROF; Rachman, 1979, 1989) refers to "reappearance of fear that has undergone partial or complete extinction" (Rachman, 1989, pp. 147), which can contribute to a complete clinical relapse of obsessional distress and functional impairment. When ROF occurs, the individual has recovered the original CS-US association, and fear returns to a higher level than was demonstrated at the end of extinction (for a review see: Craske \& Mystkowski, 2006). There are three ways in which previously extinguished fear responses might reappear.

First, spontaneous recovery refers to the fact that fear of the CS can return simply with the passage of time (Baum, 1988; Pavlov, 1927; Quirk, 2002). This is because new (non-threat) learning is most accessible immediately following the learning process (Bjork \& Bjork, 1992), and it becomes less and less accessible if not continually practiced. In contrast, the original threat association becomes progressively more accessible because it was acquired over a longer period of time and has likely generalized to multiple contexts. Thus, individuals with OCD may perform well at the end of exposure therapy, yet not maintain their gains at a later follow-up assessment.

Second, context renewal refers to ROF as a result of a context change after extinction (e.g., Bouton, 2002). Specifically, when a CS (e.g., doorknob) is paired with a US (e.g., distressing intrusive

\footnotetext{
1 We wish to thank an anonymous reviewer for also noting that although the theoretical explanations of habituation and extinction differ (as described in the present manuscript), reductions in fear during an exposure (or "WSH") can be considered analogous to fear extinction acquisition, and reductions in fear between exposure trials (or "BSH") is analogous to fear extinction recall.
}

thought/image about developing herpes) resulting in a conditioned fear response (i.e., fear, escape) in one context during fear acquisition (e.g., restroom at a gas station), and then presented (without the US) in a different context during extinction (e.g., restroom in a therapy clinic), renewal occurs when the CS is encountered either back in the original context or in a novel one (e.g., a restaurant bathroom; Bouton, 1993; Bouton \& King, 1983; Vansteenwegen et al., 2005). Thus, following extinction, the CS predicts both the occurrence and absence of the US, and the meaning retrieved is determined by the degree to which the extinction context matches the follow-up context (Bouton \& Brooks, 1993).

Complicating matters, when individuals acquire a fear-based association (e.g., doorknobs = herpes), this connection easily generalizes to new contexts (i.e., doorknobs are associated with herpes regardless of where they are; e.g., Bouton, 1994). Extinction learning, on the other hand, does not easily generalize (it is specific to the context and stimulus). Although this state of affairs is evolutionarily adaptive, it poses a challenge for exposure therapy. Rather than learning that "the CS-US relation does not hold anymore" following an extinction trial, patients only learn a context-dependent exception-to-the-rule (Eelen et al., 2001), such as, "on Mondays at 4 PM, in this particular bathroom, the doorknob-herpes relationship does not hold". In other words, these context cues interfere with durable extinction learning (Vansteenwegen et al., 2005). Much of the research we discuss subsequently focuses on understanding how therapists can maximize the likelihood that inhibitory learning will generalize across contexts.

Finally, reinstatement refers to the occasion in which unexpected presentations of the aversive US (i.e., without the CS being present) reignite fear of the previously extinguished CS (e.g., Bouton \& Swartzentruber, 1991). For example, an unexpected vivid image of developing herpes (US) could reinstate fear-based associations and expectancies of anxiety such that individuals become once again fearful of confronting OCD-related cues (CS; e.g., doorknobs in public restrooms).

The fact that these three processes can uncover original fear-based associations suggests that even with successful exposure, obsessional fear is not "unlearned" and fear-based associations do not disappear. Rather, they remain in memory and compete with newly learned nonthreat associations. The goal of exposure from an ILT perspective, therefore, is to maximize the likelihood that these new non-threat associations will inhibit the retrieval of older threat associations (A. J. Lang et al., 1999). Thus, as previously mentioned, although exposure is a highly efficacious procedure as it is traditionally implemented for OCD (i.e., using the EPT model), there appear to be additional opportunities to further enhance this intervention's long-term effects in order to better inoculate patients against later ROF.

\section{Overview of the literature review}

We next turn to a critical review of the empirical evidence regarding procedures that have been proposed based on ILT for the treatment of fear more generally (Craske et al., 2008). These procedures have in common the aim to optimize inhibitory learning in order to maximize long-term outcomes. Interest in this area is growing at a rapid pace and numerous translational studies have been conducted in the last few decades. For this review, we have a specific focus on how extinction of fear in pre-clinical anxious individuals in the laboratory may have implications for future clinical trials of exposure-based treatments for OCD. For each ILT-based procedure we: (a) provide a definition and a discussion of its derivation from ILT (i.e., theoretical rationale), (b) describe the potential applications to exposure therapy, (c) review the existing relevant empirical evidence, (d) translate this theoretical and empirical work to the treatment of OCD symptom dimensions, and (e) offer suggestions for future research.

The reader will note that a common underlying theme across ILT techniques is that instead of teaching patients to resist, control, or "fix" their fear, anxiety, or obsessional thoughts, these techniques 
promote open-mindedness towards these experiences given that they are universal, inevitable, and nonthreatening (i.e., fear tolerance). This idea is similar to the Acceptance and Commitment Therapy (ACT) framework of exposure, in which exposures can be conceptualized as behavioral exercises to facilitate psychological flexibility (i.e., willingness to experience anxiety and obsessions; Bluett, Homan, Morrison, Levin, \& Twohig, 2014; Twohig et al., 2010, 2015). In the context of ILT, fear tolerance is accomplished by introducing "desirable difficulties" (Bjork, 1994) into the implementation of exposure therapy in various ways. Such strategies (e.g., combining multiple fear cues during an exposure trial) may be considered "difficulties" because they introduce added challenges for the patient during exposure trials and often slow the rate of within- and between-session habituation of fear. On the other hand, they are "desirable," in that they are derived from ILT to maximize long-term learning by introducing ubiquitous real-world challenges (e.g., surprise) that have the added benefit of maximizing the retrieval of newly learned information (Bjork, 1994). These desirable difficulties are thought to strengthen fear tolerance (Craske et al., 2008), as patients learn that fear is an opportunity to practice managing distress, as opposed to a sign of relapse or failure.

\section{Expectancy violation}

\subsection{Definition and theoretical rationale}

Rescorla and Wagner (Rescorla \& Wagner, 1972; Wagner \& Rescorla, 1972) proposed that new information is learned when there is a discrepancy between what is predicted and what actually occurs; and that the element of surprise is critical to the learning process (Rescorla, 1988). Thus, when an individual expects a negative outcome in response to a fear trigger, and these expectancies are violated during exposure (i.e., feared consequences either do not occur or are more manageable than anticipated), a non-threat association is established. To optimize inhibitory learning (and long-term treatment outcome), therefore, therapists should question "What does the patient expect as a result of exposure to this fear cue?," and exposures should be engineered to maximally violate such expectations. Specifically, patients should remain exposed to feared stimuli (a) for longer, (b) at more intense levels, and (c) with greater frequency than they anticipate would be "safe." For instance, according to rate expectancy theory, individuals must experience fear cues (i.e., the CS) during extinction for as long or longer than the fear cue they encountered during acquisition in order to optimize extinction performance during a later testing phase (Gallistel \& Gibbon, 2000). ${ }^{2}$ This theory predicts that continuous exposures would be more beneficial than interrupted exposures because the former allows individuals to remain in contact with feared stimuli for long enough that they can violate their expectancies.

\subsection{Clinical applications}

It is important that the patient and therapist identify the specific feared consequences associated with fear stimuli (i.e., US); for example, the fear that having intrusive thoughts of stabbing someone will cause one to actually commit harm. Moreover, conditions under which the feared outcome is judged most likely to occur should be prioritized during exposure (e.g., hold a knife and think of stabbing someone while his back is turned) in order to optimally violate expectancies. As opposed to emphasizing reductions in anxiety (i.e., SUDS), exposure from this approach would involve repeated inquiries to determine whether expectations about (a) the feared outcome (i.e., "Have you stabbed anyone yet?"), and (b) the capacity to tolerate the distress associated with exposure itself have changed (i.e., expectancy tracking). The patient would continue the exposure (or repeat it) until these expectancies

\footnotetext{
${ }^{2}$ Notably, results of research applying these theories to humans has not been consistent (Prenoveau, Craske, Liao, \& Ornitz, 2013).
}

are violated (rather than until anxiety subsides). Following each exposure trial, therapists operating from this approach can help patients consolidate their learning by asking them to summarize what they have discovered and what "surprised" them, highlighting discrepancies between what they predicted and what actually occurred (Craske, Treanor, Conway, Zbozinek, \& Vervliet, 2014).

\subsection{Empirical support}

In examining rate expectancy theory, one study using rodents found that massed CS presentations during extinction (i.e., that exceeded the length of the CS during acquisition), was more effective than spaced CS trials (Cain, Blouin, \& Barad, 2003). There also exist a variety of human studies suggesting continuous in vivo presentation of fear cues (e.g., phobic stimuli, intrusive thoughts) is superior to interrupted exposure for the same duration (Chaplin \& Levine, 1981; Rabavilas, Boulougouris, \& Stefanis, 1976; Stern \& Marks, 1973); however, several studies have failed to find such differences (e.g., Mathews \& Shaw, 1973; Parkinson \& Rachman, 1980). While the assumption of these studies is that patient expectancies are being violated via continuous exposure, expectations were not explicitly measured. Furthermore, the external validity of these study designs is limited given that the acquisition context (i.e., the circumstances in which individuals acquired their fears) is typically unknown or unavailable in real world (i.e., non-laboratory) settings (Bandarian Balooch, Neumann, \& Boschen, 2012; Vansteenwegen et al., 2005).

To date, therefore, only one study has tested a priori hypotheses about the impact of continuing exposures past the point at which patients' expectancies have been violated. In that study, Deacon et al. (2013) randomly assigned participants with elevated anxiety sensitivity (AS; i.e., the fear of arousal-related body sensations) to one of four single-session interventions: (a) three 60-second interoceptive exposure trials (using hyperventilation) separated by rest periods of controlled breathing (i.e., to allow body sensations to return to baseline), (b) three 60-second interoceptive exposure trials without a rest period, (c) "intensive interoceptive exposure": 60-second interoceptive trials without rest that continued past the point at which participants expected their most feared catastrophes (e.g., heart attack) would occur and until predicted likelihood ratings of these feared consequences were $\leq 5 \%$, or (d) expressive writing (control). Compared to the other conditions, the intensive condition produced significantly greater reductions in AS and fearful responding to a straw breathing task from pre- to posttest. Furthermore, changes in fear tolerance and negative expectancies fully mediated the group differences, underscoring the role of these processes in facilitating fear extinction. One limitation of this study, however, was that the intensive group received more trials of exposure than the other groups ( $M=9.33$ vs. 3.00, respectively). Thus, it is unclear how total duration of exposure, as opposed to the expectancy violation manipulation, affected outcome.

\subsection{Applications to OCD treatment}

One consideration when applying expectancy violation to the treatment of OCD is that unlike many other anxiety disorders (e.g., phobias) in which feared consequences are fairly immediate (e.g., being bitten by a dog), the feared consequences of OCD sufferers may vary between outcomes that are immediate (e.g., "thinking about stabbing my friend will cause me to lose control and commit this act"), long-term (e.g., "I will develop cancer in 10 years from exposure to pesticides today"), and even unknowable (e.g., "I will go to hell because I had a blasphemous thought"). Hence, designing exposures to violate expectancies within the session becomes complicated. Moreover, the types of expectancies often vary with OCD symptom presentation, thus the phenomenology of each patient's OCD symptoms influence the way exposures can be designed, as we discuss next. 
Individuals with sexual, violent, and immoral/religious obsessions are especially likely to report long-term or unknowable feared consequences (e.g., "thinking this thought means I am crazy, immoral, dangerous, and damned to hell"). Not surprisingly, this presentation of OCD (sometimes called "pure obsessions") is considered especially resistant to ERP (e.g., Williams et al., 2014), perhaps because therapists attempt to use exposure (or cognitive therapy methods) to try to "disprove" such feared outcomes (e.g., testing whether someone is a child molester) when this is futile since they are not possible to prove or disprove. Obsessions involving being responsible for harm or mistakes can also incorporate long-term expectations that cannot be violated during a routine exposure session; for example, fears that leaving doors unlocked or lights on when leaving the house will lead to a burglary or fire while not at home.

Instead of trying to disprove long-term or unknowable feared outcomes, exposures for these presentations of OCD should be reframed to identify (and violate) more immediate expectations, which are often overlooked. These include the expectation that one will not be able to tolerate (a) thinking obsessional thoughts, (b) uncertainty about the feared consequences, and/or (c) anxious arousal associated with confronting feared stimuli. Specifically, expectancy tracking can be used to help patients exceed their expectations about being able to continue exposure while feeling anxious, uncertain, and having obsessions. During this process, the therapist highlights that the patient can tolerate anxiety, uncertainty, doubts, and other unwanted obsessional stimuli at higher intensity and at longer duration than was expected. For example, a patient afraid of developing cancer years later as a result of exposure to pesticides in a home and garden store might practice remaining in the pesticide aisle while purposely thinking about being unsure whether he or she might one day develop cancer as a result.

Expectancy tracking can also be used to help individuals with OCD learn that they can tolerate emotions other than fear and anxiety that sometimes present with this condition. For example, patients who present with contamination obsessions that involve disgust (rather than a focus on harm-related outcomes) often hold beliefs that disgust will persist indefinitely and become intolerable (e.g., "I can't stand the feeling"). Here, exposures can use expectancy tracking to help such patients discover that their negative appraisals of disgust are unfounded; rather, that they can endure and manage such feelings-despite their unpleasantness-even if they persist longer and at higher intensities than desired. An analogous situation arises with "not-just-right" experiences (NJREs), which are often similarly appraised as unmanageable (Coles, Frost, Heimberg, \& Rhéaume, 2003; Coles, Heimberg, Frost, \& Steketee, 2005). Here, expectancy violation can be used to help patients provoke NJREs and resist ritualizing (e.g., ordering or arranging) to discover that these uncomfortable experiences are more manageable than expected. We have observed therapists using exposure from an EPT perspective in an attempt to bring about the habituation of disgust and NJREs; however, research indicates that unlike anxiety and fear, these other experiences do not habituate as readily (e.g., Olatunji, Wolitzky-Taylor, Willems, Lohr, \& Armstrong, 2009).

Expectancy violation may also have implications for the use of cognitive therapy (CT) along with exposure. Many therapists use CT before or during exposure practices for the purpose of correcting patients' predictions about feared consequences and preparing (or motivating) them to face their fears. Some therapists feel that CT is necessary to make exposure tasks more palatable for patients. Nevertheless, an important tenant of expectancy violation is that extinction learning is strengthened when the discrepancy between what patients expect and what actually occurs is maximized. Although no empirical studies have addressed this question, Craske et al. (2014) suggest that strategies aimed to reduce this discrepancy prior to exposure will negatively impact extinction learning. Accordingly, CT, which is used to correct exaggerated overestimates of likelihood ("I am unlikely to get cancer from the pesticide aisle") and severity (e.g., "Uncertainty is universal and tolerable") of feared outcomes may actually attenuate inhibitory learning when used prior to, or during, exposures. In other words, paradoxically, CT may reduce negative expectancies prior to exposure and thus lessen the mismatch between prediction and outcome.

\subsection{Suggestions for future research}

There is currently a dearth of empirical data addressing the utility of expectancy violation in exposure. Thus, we caution that more studies are needed before clinical practice gets too far ahead of the data-especially in the area of OCD. One direction for future research is to conduct between-groups comparisons in which (a) exposure with expectancy tracking and violation of fear-based predictions is compared to (b) exposure in which patients merely track their level of distress for a matched length of time during exposure tasks. A second informative avenue of study given hypotheses about CT's presumed effects on inhibitory learning would be to compare the effects of using CT to challenge exaggerated threat predictions before exposure begins (i.e., as is traditionally done) compared to after each exposure (i.e., in order to consolidate what was learned). It will also be important to better understand the parameters of expectancy violation of the longer-term and unknowable feared consequences (e.g., intolerance of uncertainty) that are often observed in individuals with OCD. Dependent variables in these types of studies might be the strength of participants' beliefs that feared consequences will occur or persistence of avoidance behaviors (e.g., as measured using behavioral approach tasks); rather than global symptom measures (which may not be sensitive to nuanced changes) or measures that solely focus on fear reduction (which can be seen as contrary to goals of fear tolerance).

Given the limitations of the study by Deacon et al. (2013), future work should ensure that experimental groups are equated for total exposure time. It would also be important to include multiple post-intervention (i.e., follow-up) assessments to examine the stability of any findings given that the ILT approach emphasizes enhancing long-term learning. Moreover, because different presentations of OCD include qualitatively different feared consequences/expectations, conducting such experiments with homogenous sub-groups of patients with OCD (e.g., all illness-related contamination concerns) or analogues with similar types of obsessional experiences (e.g., intrusive sexual thoughts) would be especially informative.

\section{Combining multiple fear cues}

\subsection{Definition and theoretical rationale}

The Rescorla-Wagner model (1972) predicts that another method for introducing desirable difficulties (and thus promoting inhibitory learning) into exposure therapy is to combine multiple fear cues during exposure trials, as opposed to only presenting one fear cue at a time. Combining fear cues is thought to increase the discrepancy between fear-based expectations and actual outcomes. In other words, when an expected feared outcome does not occur despite the simultaneous presence of multiple fear cues, inhibitory learning should be greater than when only one fear cue is present. Rescorla (2006) used the term "deepened extinction" to describe the process of sequentially extinguishing fear responses to two or more stimuli before subsequently combining the stimuli for additional extinction learning. Similarly, "super extinction" (Rescorla \& Wagner, 1972) refers to simultaneously extinguishing fear responses to two or more stimuli without separate prior extinction.

\subsection{Clinical applications}

The most common approach to exposure involves confrontation with an external feared situation or stimulus, such as public speaking, dogs, or in the case of OCD, a public toilet. Situational exposure, however, is not 
the only way to generate new learned associations. A variety of verbal, imaginal, and physiological modalities can be used to facilitate long-term extinction learning because the experience of pathological fear involves behavioral avoidance, maladaptive cognitions (e.g., exaggerated perceptions of threat), and increased physiological responding (e.g., racing heart). Accordingly, verbal descriptions, digital media (e.g., audio recordings, movies), and interoceptive exercises may be engineered to contain the required information to mismatch a patient's fear-based expectations (e.g., "I will become ill"; "I can't tolerate being uncertain about germs"; "Anxiety will persist forever"). With these different modalities at the therapist's disposal, the concept of combining multiple fear cues can be easily translated into exposure therapy via the use of "multi-media exposures." Such exposures might incorporate external (e.g., contact with feared contaminants), cognitive (e.g., verbal stimuli to evoke obsessional doubts), and physiological (e.g., hyperventilation) cues in combination.

\subsection{Empirical support}

In one of the first animal studies implementing a "deepened extinction" paradigm (Rescorla, 2006, Experiment 1), rats in the control group who had only undergone extinction to the two CSs separately (a noise and a light that had each been paired with a shock), experienced more ROF compared to the deepened extinction group (i.e., who had also undergone extinction to the two stimuli presented concurrently). In other words, the extinction trials that combined multiple fear cues after they had been presented separately deepened the animals' learning compared to presentation of a single cue.

Only one study to date with humans has investigated whether deepened extinction enhances inhibitory learning. Using a between-subjects de novo fear conditioning paradigm in a sample of individuals with elevated behavioral inhibition (i.e., a vulnerability to developing anxiety disorders), Culver, Vervliet, and Craske (2014) first individually paired two geometric shapes with a loud 1-second scream until participants acquired a conditioned fear response to each shape presented separately. Next, the fear response to each shape was extinguished separately (by presenting the stimuli alone without the scream). After initial extinction, participants were randomly assigned to one of two possible second extinction phases (without the scream): (a) exposure to each shape alone (control group), or (b) exposure to both shapes together (deepened extinction group). When both groups were tested one week later, the control group experienced greater ROF (spontaneous recovery and reinstatement of fear) relative to the deepened extinction group. Furthermore, a subset of participants ingested $600 \mathrm{mg}$ of caffeine, which had limited impact on ROF. This indicates that the mechanism of action may specifically be the discrepancy between expectations and reality rather than heightened physiological arousal during extinction learning.

Human research on super extinction, however, suggests a different picture (Lovibond, Davis, \& O'Flaherty, 2000, Experiment 2; Vervliet et al., 2007). For example, in a within-subjects experimental design, Vervliet et al. (2007) paired electric shocks with two images of shapes presented on a computer screen. During an extinction phase, these two shapes were presented together without the shock and without individual extinction trials. Later, when one shape was presented individually, participants experienced a strong ROF that was comparable to pre-extinction fear levels; this effect was not observed in nonconditioned (control) shapes that were never paired with a shock. This finding is in contrast to traditional theories of super extinction (Rescorla \& Wagner, 1972), and with animal studies demonstrating support for this phenomenon (Thomas \& Ayres, 2004, Experiment 4). One explanation for this discrepancy is that in humans the compound presentation of stimuli creates a novel CS to which the new extinction learning is uniquely applied; i.e., it does not generalize to either CS presented alone (Vervliet et al., 2007).

\subsection{Applications to OCD treatment}

As we have discussed, most individuals with OCD experience intrusive anxiety-evoking obsessional thoughts, doubts, and images regarding feared outcomes that are typically triggered by external situations and stimuli. Whereas situational exposure to tangible fear cues such as dirt or unlucky numbers is straightforward, confrontation with future or unknowable feared consequences (e.g., going to hell, causing a fire, contracting an illness) is not. A woman afraid of causing fires, who therefore constantly checks whether her stove is turned off, can be exposed in vivo by requiring her to pre-heat the oven while taking the dog for a walk around the yard. However, ethically, she cannot be exposed to actually causing a fire as a result of not carefully checking her stove. Confrontation with such feared outcomes must, therefore, be conducted in imagination. It follows from our discussion to this point regarding the importance of maximally violating expectancies and combining fear cues during exposure that obsessional fears should optimally improve when imaginal exposure to feared outcomes is incorporated along with situational exposure. Similarly, whereas we might think of interoceptive exposure in the context of treatment for panic disorder (Barlow \& Craske, 2007), it can also be incorporated in exposure for OCD when fear associations include the fear of one's own anxiety/arousal-related responses (e.g., "I cannot tolerate a racing heart"), as we discuss next.

Obsessions concerning responsibility for harm lend themselves very well to combining exposure media. The woman with a fear of causing a house fire might also describe how her anxious arousal "clouds her memory" and makes her feel even more uncertain of whether she turned off her stove. Exposure could involve (a) purposely inducing physiological arousal using interoceptive exposure (e.g., hyperventilating), (b) situational exposure to leaving her home in a rush without double-checking the stove, and then (c) imaginal exposure to not knowing whether she has caused a fire. Structuring exposure therapy in this way would create mismatches with the patient's expectations that (a) anxious arousal will cloud her memory, (b) fires are likely, and (c) she can't manage the resulting uncertainty.

Obsessions involving sexual thoughts (and some violent or moral obsessions) may also necessitate the combining of these three exposure media. Patients with obsessional doubts of a sexual nature, such as "what if I am attracted to young children?" can be exposed to external stimuli such as a trip to the playground, and imaginal exposure to engaging in sexual behavior with a child. Often, individuals with such obsessions misinterpret their anxious arousal as confirmation that their obsessions are realistic; for example, "when I see a child and my heart races, it means I'm sexually turned on." Many patients subsequently become body vigilant and engage in reassurance-seeking to try to verify the "true source" of their physiological sensations (anxious vs. sexual arousal). This provides material for both interoceptive exposure to physiological arousal and imaginal exposure to the uncertainties of what thoughts about molesting children and physical sensations might or might not "really" mean. Introducing such extra "difficulties" by combining multiple fear cues in the same exposure can produce desirable long-term outcomes and opportunities to practice tolerating multiple stimuli at once.

Finally, therapists can also take advantage of opportunities to incorporate imaginal and interoceptive exposure for individuals with contamination and asymmetry/incompleteness obsessions. Specifically, imaginal exposure can be used to develop new nonthreat associations with thoughts and doubts evoked by situational exposure (e.g., imagining the HIV virus infecting one's body after touching the hand railing of the hospital stairs; imagining bad luck befalling oneself after disorganizing the desk drawer). Interoceptive exposure can be used similarly if the patient's fear is evoked by bodily sensations (e.g., tiredness associated with HIV; feelings of anxious apprehension misinterpreted as omens of bad luck). 


\subsection{Suggestions for future research}

Studies of clinical samples are needed to further examine whether using deepened and super extinction techniques leads to enhanced short- or long-term outcomes. Moreover, it would be informative to determine the manner in which fear stimuli should be optimally combined. For example, as the idea of deepened extinction would suggest, should clinicians take the time to conduct exposures to each type of fear cue separately before they are combined so patients learn they can handle these cues alone and in combination with one another?

\section{Maximizing contextual variability}

\subsection{Definition and theoretical rationale}

As previously mentioned, context renewal refers to a return of the conditioned fear response as a result of a change in context after extinction. For example, consider a patient whose fear of knives appears to undergo extinction after multiple in-session exposures; yet when she handles a knife at home in the presence of her newborn infant, her fear of knives is rekindled. Numerous studies show that, indeed (perhaps for evolutionary reasons), fear learning easily generalizes across contexts, yet inhibitory (i.e., safety) learning does not (e.g., Bouton, 1994). Accordingly, ROF can occur when extinction learning (i.e., exposure therapy) occurs under one set of conditions, but the stimulus is subsequently encountered under a different set of conditions.

One option for protecting patients against context renewal is to introduce contextual variability during exposure trials. Although practicing exposure under variable conditions can make learning and retrieval more difficult in the short-term, researchers have suggested three reasons that this confers long-term benefits as compared to restricting exposure to a single context (i.e., "desirable difficulties"; e.g., Bjork \& Bjork, 1992, 2006; Rescorla \& Wagner, 1972; Schmidt \& Bjork, 1992). First, the repeated practice affords more opportunities for corrective learning to occur and therefore promotes greater storage and retrieval strength to enhance long-term retention. Second, the more diverse the conditions under which learning takes place, the greater number of retrieval cues that are generated. These cues trigger memories of the learning that occurred during exposure, which improve generalizability of learning. Third, learning is maximized when the learner has to engage in analyzing, evaluating, and synthesizing what is being learned (as opposed to simply remembering) in order to develop a common strategy for handling fear cues across contexts.

\subsection{Clinical applications}

"Context" can be defined broadly as any condition or set of conditions (internal or external) under which learning occurs; thus, when considering applications to exposure therapy, the presence of nearly any stimulus could become a context and impact long-term extinction (Bouton \& Swartzentruber, 1991). Three pertinent context domains include (a) exposure stimuli themselves (i.e., the specific situations and stimuli that patients confront; e.g., exposure to multiple violent movie scenes); (b) the external environment (i.e., the surroundings in which exposure occurs; watching violent movie scenes alone versus with a therapist); and (c) physiological states (e.g., the level of emotional intensity during exposure; e.g., watching violent scenes after drinking caffeine versus in a more relaxed state). Considering the importance of the context in which learning (i.e., exposure) takes place for later retrieval of extinction learning, exposures should be conducted with multiple clinically meaningful exposure stimuli, in multiple different environments, and under conditions of varying levels of anxious (physiological) arousal. In the sections that follow, we review the empirical support for each of these three domains.

\subsection{Empirical support}

\subsubsection{Exposure stimuli}

Individuals who undergo all extinction learning (i.e., exposure) trials with the same exposure stimulus (e.g., the same office trash can) would be expected to show failed generalization of learning when confronted with a novel stimulus (e.g., a different type of trash receptacle) than would those who conduct exposure using multiple different stimuli (e.g., various types of trash cans; Vervliet, Vansteenwegen, Baeyens, Hermans, \& Helen, 2005; Vervliet, Vansteenwegen, \& Eelen, 2004). Only one study to date has tested the hypothesis that varying stimuli during exposure therapy is superior to relying on one stimulus alone. In a pre-clinical sample of spider fearful individuals, Rowe and Craske (1998b) found that conducting exposure using four spiders of different size, appearance, and quickness (i.e., variable stimulus exposure) resulted in less habituation of anxiety (i.e., worse performance) during exposure trials relative to when exposure was conducted with only one type of spider (i.e., constant stimulus exposure). When, however, both groups were presented with a previously seen spider at 3-week follow-up, the variable-stimulus group displayed less ROF than did the constant-stimulus group. Contrary to the hypothesis that receiving varied-stimulus exposure results in generalization of safety learning, however, there were no group differences when a novel spider was presented at follow-up.

\subsubsection{External environment}

Individuals who undergo all extinction learning trials with a fear stimulus under the same surrounding conditions (e.g., in the therapist's office) would be expected to show greater ROF if faced with the same stimulus in a novel environment (e.g., at home without the therapist present) than would those who conduct exposure under different conditions (e.g., with and without the therapist present; Mystkowski, Craske, \& Echiverri, 2002). Yet only a single study has empirically addressed the effects of conducting exposure therapy in multiple environmental contexts. Again with spider-fearful individuals, Vansteenwegen et al. (2007) found that individuals who watched videotapes of a spider located in multiple rooms of a house showed a generalization of extinction learning relative to those who repeatedly watched videotapes of the spider in the same room. Specifically, among the varied environment group, there was no significant difference in skin conductance and self-reported fear levels when participants were shown a videotaped spider in a previously seen location of the house versus a new location. Of course, a limitation of this study is that the exposure and post-test stimuli were videotapes, as opposed to actual spiders.

\subsubsection{Physiological/interoceptive}

Individuals who conduct all exposure trials under one physiological state (e.g., no caffeine) would be expected to show greater ROF in an incongruent physiological state (e.g., caffeine) than would those who conduct exposure under various internal conditions (e.g., with and without caffeine; Bouton \& Swartzentruber, 1991; Mystkowski, Mineka, Vernon, \& Zinbarg, 2003). ${ }^{3}$ Several studies have indeed indicated that variability of fear responding during exposure predicts improved long-term outcome (although see Meuret et al., 2012 for null findings). For example, in samples of individuals fearful of public speaking (Culver, Stoyanova, \& Craske, 2012) and contamination (Kircanski et al., 2012), variability in subjective fear during exposure predicted lower self-reported fear levels at follow-up testing. Thus, individuals who learned to tolerate varying levels of anxious arousal during exposure demonstrated superior long-term outcomes (compared to those who experienced circumscribed variability in fear levels).

\footnotetext{
3 Additionally, studies with rodents report mixed findings as to whether use of yohimbine (an alpha-2 adrenergic antagonist that sustains fear responding) facilitates extinction learning (Cain, Blouin, \& Barad, 2004); see Mueller, Olivera-Figueroa, Pine, and Quirk (2009) for a study that failed to replicate this finding.
} 
In addition, a few studies have examined whether variability in fear responding can be experimentally induced with variable exposure, as opposed to the typically used gradual exposure. Lang and Craske (2000; experiment 1) found that when participants with fears of heights practiced exposures in a random order (e.g., 7th floor, 2nd floor, 5th floor, 10th floor, etc. of a tall building) and approached the balcony in a different manner at each trial (e.g., leaning on the railing vs. looking down), higher levels of fear (self-report and HR) were observed during exposure, yet lower self-reported general anxiety (although not fear of heights in particular) were observed at 1-month follow-up relative to participants who gradually progressed up the floors and approached the balcony in a uniform way.

On the other hand, two experimental studies failed to support the theory that varying the intensity of anxiety during exposure can enhance long-term outcomes. Despite improvement across both treatment conditions, Kircanski et al. (2012) found no differences at 2-week follow-up for groups of individuals with contamination fears assigned to 3 sessions of either gradual (hierarchically-guided) or variable (i.e., randomly chosen items) exposure. Similarly, Culver et al. (2012) found no difference in fear responding following exposure for public speaking fears that was either accompanied by additional excitatory stimuli (e.g., a tightened workman's belt designed to cause the sensation of chest tightness) or not. Taken together, the available studies investigating variability in exposure intensity (and corresponding physiological arousal) suggest that while individual differences in variability of fear during exposure indeed predict long-term outcome, experimental manipulations of arousal levels produce more mixed results.

\subsection{Applications to $O C D$ treatment}

Generally speaking, patients' obsessional fears-even those that seem circumscribed-are provoked by a range of stimuli that may be more or less evocative (Abramowitz \& Jacoby, 2014). For example, one might be afraid of trashcans, yet believe that trashcans with a lid are more dangerous than those without a lid because the former require lifting the lid (and hence more contact) to dispose of trash. In addition, trashcans used for disposal of food might provoke more distress because food could spoil, emit unpleasant odors, and attract bugs; whereas office trashcans used for disposing of paper do not have a smell. Trash containers used for biohazards might be perceived as especially contaminated because they contain bodily fluids. Accordingly, a patient with fears of "trashcan germs" might conduct exposures to trashcans of varying forms (with and without a lid) and purposes (food, office supplies, biohazards). Similarly, someone with fears of stabbing loved ones with household items might conduct exposures to different types of "weapons" (e.g., scissors, knives), of different size (e.g., butter knife, carving knife), and sharpness (e.g., dull, serrated). Therapists might expect that conducting exposures with variable stimuli will slow fear habituation during the learning process, yet reduce long-term ROF.

With regard to varying the environmental context of exposure, an individual with fears of being responsible for a burglary might practice leaving both her home and office without checking the locks. Those with fears of hitting a pedestrian with their car might practice driving in both daytime and nighttime. Touching contamination stimuli and then eating can be conducted in the therapist's office, at home, and at restaurants. Similarly, imaginal exposure can be conducted in different settings, such as purposely thinking about pedophilia in the therapist's office, while at a playground, at a zoo, inside a school, and even while playing with children or changing a baby's diaper. Or one might conjure up blasphemous images while at home, near a cemetery, and while in a place of worship (empty and during a service).

Finally, one potential means of fostering physiological variability is to have the patient conduct exposure under conditions of varying levels of anxious arousal. This can be accomplished by varying the intensity of exposures rather than structuring them in a systematic and gradual way (as is traditionally done to foster habituation; e.g., Foa et al., 2012). For example, instead of following a hierarchy, patients may maximally benefit from treatment plans in which exposure tasks of differing levels of fear provocation are selected at random (as long as both the patient and therapist agree to this approach in advance). This might foster extinction learning by teaching the patient that he or she can tolerate any level of anxiety/distress, in any order and at any time. This is in contrast to hierarchy-driven exposure which risks fostering the idea that the highest hierarchy items provoke such unbearable anxiety that the patient has no choice but to "work up to it". Furthermore, random and varied exposure practice might help inoculate patients against ROF since it most closely parallels actual experiences the patient will have with feared stimuli following therapy. As can be explained to patients who might balk at such an approach, encounters with obsessional stimuli and situations do not naturally occur in a gradual and hierarchical manner in the real world!

Another method is to select exposures on the basis of life interference, an idea which is consistent with ACT frameworks of exposure (Twohig et al., 2015). For example, a patient with unacceptable intrusive thoughts that deep down he is a child molester may decide to engage in an exposure where he "roughhouses" with and tickles his 4year old nephew (SUDS $=90$ ) before conducting later imaginal exposure to related words (e.g., molest, child; SUDS $=40$ ) or pictures (e.g., children's clothing catalogs; SUDS $=50$ ), so that he can spend time with his family again as soon as possible. Conducting exposures in these ways allows patient goals and values to drive the progression of treatment, introduces desirable difficulties, fosters fear tolerance, and does not over-rely on habituation of anxiety. Although we caution readers that to date there are no pre-clinical or clinical studies for more complex anxiety problems than specific phobias (e.g., heights and spiders), the potential benefits of varying exposure contexts seem worthy of clinical attention and future research as we discuss next.

\subsection{Suggestions for future research}

Additional studies are needed to determine the most salient contexts to vary; in other words, which characteristics of stimuli and environments are most clinically meaningful for each individual and how can variability of these stimuli be maximized? Then, research can examine differential outcomes when some individuals conduct exposures to the same stimuli repeatedly (e.g., same trashcan) and others conduct exposures to varying stimuli (e.g., different trashcans). Additionally, comparing outcomes when feared stimuli are only confronted in one environment (e.g., therapist's office) versus in multiple locations (e.g., in the office, at home, at work, etc.) will help elucidate the importance of varying environmental context. As previously mentioned, it is important that outcomes in these studies include not only self-report and clinical interview measures of fear, but also directly investigate behavioral performance when faced with a previously seen and a novel stimulus/environment.

Finally, study designs that compare the utility of a gradual (i.e., hierarchical) approach to exposure versus a random/variable approach will help researchers determine the degree to which physiological arousal can be manipulated, whether varying the level of fear/arousal predicts treatment outcome, and the acceptability of this approach to patients. We are currently conducting such a study that compares the process and outcomes (self-report, interview, behavioral, and psychophysiological) of gradual versus variable approaches to exposure for individuals with obsessional thoughts.

\section{Expanding the inter-session interval}

\subsection{Definition and theoretical rationale}

There are theoretical reasons to support the hypothesis that expanding the time interval between exposure sessions (Bjork \& 
Bjork, 2006) is beneficial for long-term outcome. Massed practice (i.e., closely spaced learning episodes), on the one hand, may produce higher initial levels of retrieval strength and thus better short-term performance. For example, cramming all day may be useful if a student has an exam the next day. However, research suggests that information learned during massed practice is forgotten soon after practice ends, which leaves patients vulnerable to later ROF (Schmidt \& Bjork, 1992). Distributed practice (i.e., longer and more varied time intervals between learning episodes), on the other hand, might make learning more difficult and impair short-term performance (Schmidt \& Bjork, 1992), yet it results in higher storage strength and enhances long-term retention of what was learned (Bjork \& Bjork, 1992). This occurs for two primary reasons. First, spaced practice provides more opportunities to forget and practice re-learning information (which creates more "surprising" conditions for new learning). Second, it provides opportunities to rehearse, consolidate, and generalize new learning across various contexts. Thus, the "spacing effect" (Bjork \& Bjork, 2006) suggests that distributed practice is preferred when the retention interval is longer (e.g., students need to remember information not only for an upcoming exam but also for a cumulative final exam at the end of the semester). In a similar vein, the goal of exposure therapy is for anxious patients to learn new non-threat associations to be retained long-term.

\subsection{Clinical applications}

Although it is understandable for clinicians to seek rapid short-term progress using massed practice (to maximize retrieval strength), as we allude to above, doing so jeopardizes opportunities to capitalize on desirable difficulties and maximize long-term outcomes (storage strength). In fact, rapid progress may be a sign that retrieval strength is being accumulated at the expense of storage strength (Bjork \& Bjork, 2006). Instead, when there are longer intervals between exposure sessions, retrieval of the new non-fearful responses in a therapy session might be more difficult, but this results in enhanced long-term learning.

The precise interval between exposure trials should be carefully selected so that new learning is challenging (i.e., there is a reduction of retrieval strength), but also successful. "Expanding spaced scheduling" refers to scheduling each trial at the point in time at which retrieval is maximally difficult but still possible (Landauer \& Bjork, 1978), which may change (i.e., expand) over the course of treatment. Thus, exposure trials might begin at twice per week, then occur once per week, then every other week, and so on. Indeed, research has demonstrated potential benefits of expanding learning trials (e.g., Landauer \& Bjork, 1978). As described next, additional evidence with clinically anxious individuals is needed to determine the optimal length between sessions.

\subsection{Empirical support}

Studies have compared massed to expanding interval exposures in individuals with pre-clinical fears of spiders (Rowe \& Craske, 1998a), heights (A. J. Lang \& Craske, 2000, Experiment 2), and public speaking (Tsao \& Craske, 2000). The number of sessions and the cumulative quantity of exposure was kept constant in each study. While Lang and Craske (2000) failed to find evidence of ROF in either massed or expanding spaced exposure, both Rowe and Craske (1998a) and Tsao and Craske (2000) demonstrated benefits of an expanding schedule (e.g., 1 day, 2 days, 4 days, 8 days between sessions) relative to a massed schedule (i.e., 4 exposure trials on the same day). In both studies, the massed group experienced more ROF as measured by self-report (Rowe \& Craske, 1998a; Tsao \& Craske, 2000) and HR (Tsao \& Craske, 2000) at 1-month follow-up. Such differences, however, were not observed on a behavioral approach task. The effects of spacing during extinction training have been inconsistent in animal samples (for a review see: Craske et al., 2008).

\subsection{Applications to OCD treatment}

As reviewed previously, the available literature addresses expanding spaced exposure for relatively specific and avoidable (to a greater or lesser extent) stimuli (i.e., spiders, public speaking, heights) as might be observed in phobias. In OCD, however, individuals often have fear cues that are unavoidable and recurring, such as using the bathroom, unpleasant thoughts, uncertainty, and asymmetry. This presents challenges when trying to systematically space the frequency of confronting such cues in exposure. For example, someone with fears of "urine germs" in effect has opportunities for exposure every time they use the bathroom-which might be multiple times per day. Thus, massed exposure might be unavoidable. In a study comparing spaced (twiceweekly) and massed (5 times weekly) ERP for OCD, however, Abramowitz, Foa, and Franklin (2003) found evidence that in session exposure with therapist supervision is more critical to outcome than is the total number of exposure trials (including those that occur outside the session). Thus, clinicians might not need to be overly concerned about homework-based massed exposure attenuating the effects of insession expanding spaced exposure trials.

In addition, it is important to consider when patients with OCD should receive massed versus expanding spaced exposure. Although expanding spaced ERP might optimize long-term results for some patients, this schedule will not be ideal for everyone with OCD. Accordingly, the pros and cons of spaced vs. massed exposure should be considered. A benefit of massed exposure is that it allows for close supervision of exposure practice and rapid identification (and addressing) of noncompliance (Abramowitz, Franklin, Zoellner, \& DiBernardo, 2002). Thus, we recommend massed exposure when there are concerns about the following: poor insight into the senselessness of OCD symptoms, difficulty comprehending the rationale for ERP, difficulty with response prevention, and family member accommodation. Expanding spaced sessions would be optimal when patients do not balk at exposure and demonstrate that they are capable of refraining from rituals between sessions. Additional research should examine these aforementioned moderators of response when using these two schedules of treatment.

\subsection{Suggestions for future research}

As alluded to, replications with OCD patients comparing massed vs. spaced vs. expanding schedules are warranted. Systematic investigations are needed in order to determine the optimal expansion schedule. Furthermore, studies should more closely examine homework practice in massed vs. expanded scheduling formats, given that exposure practice between sessions is an integral part of ERP treatment packages (Foa et al., 2012). Homework practice may especially benefit those with presentations of OCD that cannot be fully replicated in the therapist's office (e.g., responsibility for harm when leaving one's home).

\section{Conclusions, limitations, and future directions}

Exposure-based therapy is the most empirically supported intervention for problems in which pathological fear is maintained by exaggerated beliefs about danger that lead to maladaptive escape/avoidance behavior. Craske et al. (2008) have pointed to limitations of the traditional EPT framework for understanding how exposure therapy works and how it can be implemented. On the basis of basic research on fear extinction, they propose a framework for exposure in which inhibitory learning is optimized to enhance long-term outcome. This research and the corresponding clinical recommendations (e.g., Craske et al., 2014) have primarily focused on the treatment of phobic and anxiety disorders (e.g., specific phobias), to the exclusion of more complex presentations of fear, such as that observed among the dimensions of OCD. We provide an up-to-date critical review of the existing empirical literature on humans that has accumulated within this rapidly accelerating 
area of study. We also broaden the application of this research to the OCD symptom dimensions.

Overall, the empirical literature evaluating hypotheses derived from the inhibitory learning approach to exposure is still in its nascent stages. While it is not possible to draw definitive inferences at this juncture, we can tentatively conclude that introducing challenges to make learning more difficult during exposure trials (i.e., "desirable difficulties") maximizes long-term outcome. First, there are preliminary data to suggest that exposure can be structured to violate patient expectancies about anxiety, uncertainty, and feared consequences to enhance long-term fear extinction. When working with individuals with OCD, it is important to consider that the expectancies to be violated may be both short-term feared consequences, as well as long-term or "unknowable" outcomes. Moreover, expectancies might extend beyond fear-related predictions to those associated with not being able to tolerate experiences such as uncertainty, disgust, and incompleteness (i.e., "not just right" experiences).

Second, while basic laboratory research (i.e., de novo fear conditioning) indicates that combining multiple previously extinguished fear cues can enhance extinction learning, this work has not yet been translated to clinical or even pre-clinical samples. Provided that these hypotheses are supported, the treatment of OCD lends itself well to the use of multiple fear cues during exposure. Indeed, obsessional fear can be triggered by external stimuli (e.g., bathrooms), anxiety-evoking thoughts and doubt (e.g., about germs spreading over one's body), and physiological responses and interoceptive cues (e.g., heart racing, sensations in ones genitals) which can be confronted separately at first, and subsequently simultaneously. Third, varying exposure stimuli and environmental locations appear to help generalize extinction learning across contexts and prevent ROF in specific phobias. Replication with more complex presentations of fear (e.g., OCD) is needed, however, as indicated by the various ways contextual variability can be maximized across the OCD symptom dimensions. Moreover, there is consistent evidence that variability of physiological responding predicts outcome; however, studies that have attempted to experimentally induce physiological variability by comparing systematic and gradual (i.e., hierarchical) exposure to random and variable exposure have reported mixed findings. If experimental designs can induce variability in exposure, this might be especially useful in the treatment of OCD given that encounters with obsessional stimuli and situations do not naturally occur hierarchically in daily life.

Finally, evidence suggests that gradually expanding the interval between therapist-guided exposure sessions (so that exposure is conducted when retrieval is maximally difficult but still possible) leads to enhanced long-term learning despite the sacrifice of short-term progress; however the optimal expanding schedule is unknown. Fear cues for individuals with OCD are often unavoidable and recurring, which presents barriers to spacing the frequency of exposure. However, previous research suggests that in-session therapist guided exposure predicts treatment outcome, which suggests that homework-based massed exposure would not interfere with expanding spaced insession exposure trials.

This body of research is not without limitations, however. Most notably, as mentioned throughout, there are various examples of failure to replicate findings. Furthermore, even when results seem to support inhibitory learning theory, there is often a disconnect between the three fear response systems-verbal, behavioral, and physiological-such that long-term benefits are demonstrated with, for example, verbal (e.g., SUDS) but not physiological (e.g., heart rate) indices. Additionally, the majority of studies in this area seek to maximize internal validity, and thus either examine the extinction of de novo conditioned fears in healthy individuals or of pre-existing fears in analog anxious individuals in the laboratory.

Questions remain unresolved, therefore, regarding the clinical utility of these inhibitory learning modifications and how these findings will generalize to treatment-seeking samples in actual clinical settings.
Participants in many studies were not provided treatment rationales (e.g., clear explanations of how variability can introduce desirable difficulties and foster fear tolerance) as would occur in clinical practice. Therefore, there is a need to examine the effects of these rationales on treatment credibility, acceptability, as well as on engagement in exposure and treatment outcome. Moreover, in the studies reviewed here, "long-term" outcome is typically operationalized as one week or one month post-treatment, which is not as relevant to clinical settings where it is hoped that patients would maintain their improvements for months or years. As we have noted, the existing literature provides ample opportunities for future research to further translate experimental findings on inhibitory learning and memory to larger scale effectiveness and efficacy studies. Given the dearth of existing data on OCD, future work should also address how these principles apply to the various OCD symptom dimensions.

As a final thought, on the basis of our clinical experience and the research reviewed presently, we believe clinicians need not completely abandon the EPT model when implementing exposure. Indeed, habituation is a natural process that is at the very least an indicator of change in how the patient is experiencing a fear cue in the moment. As long as no safety behaviors or rituals are used to reduce anxiety, habituation is not inherently problematic and can be noted during exposure. Nevertheless, over-reliance on habituation could foster a "fear of fear" mindset and lead to outcomes in which the non-occurrence of habituation or the random appearance of anxiety and fear come to be perceived signs of failure. Accordingly, we recommend that clinicians engineer exposure tasks to help patients practice tolerating fear, anxiety, and uncertainty in order to reduce secondary distress (i.e., anxiety about anxiety), improve quality of life, and maximize long-term outcomes. From this "desirable difficulties" perspective, habituation of anxiety becomes a pleasant side effect of exposure (that often, but not always occurs) rather than a requirement for success.

\section{Acknowledgments}

The authors wish to thank Dr. Donald Baucom, Dr. David Penn, and Benjamin Buck who provided comments and suggestions on an early draft of this manuscript.

\section{References}

Abramowitz, J. S., \& Arch, J. J. (2014). Strategies for improving long-term outcomes in cognitive behavioral therapy for obsessive-compulsive disorder: Insights from learning theory. Cognitive and Behavioral Practice, 21, 20-31. http://dx.doi.org/10.1016/j. cbpra.2013.06.004

Abramowitz, J. S., Deacon, B. J., Olatunji, B. O., Wheaton, M. G., Berman, N. C., Losardo, D., ... Hale, L. R. (2010). Assessment of obsessive-compulsive symptom dimensions: Development and evaluation of the dimensional obsessive-compulsive scale. Psychological Assessment, 22(1), 180-198.

Abramowitz, J. S., Deacon, B. J., \& Whiteside, S. P. H. (2011). Exposure therapy for anxiety: Principles and practice. New York, NY: Guilford Press.

Abramowitz, J. S., Foa, E. B., \& Franklin, M. E. (2003). Exposure and ritual prevention for obsessive-compulsive disorder: Effects of intensive versus twice-weekly sessions. Journal of Consulting and Clinical Psychology, 71(2), 394-398. http://dx.doi.org/10. 1037/0022-006X.71.2.394.

Abramowitz, J. S., Franklin, M. E., Zoellner, L. A., \& DiBernardo, C. L. (2002). Treatment compliance and outcome in obsessive-compulsive disorder. Behavior Modification, 26(4), 447-463. http://dx.doi.org/10.1177/0145445502026004001.

Abramowitz, J. S., \& Jacoby, R. J. (2014). Obsessive-Compulsive Disorder in Adults. Boston, MA: Hogrefe Publishing.

Baker, A., Mystkowski, J., Culver, N., Yi, R., Mortazavi, A., \& Craske, M. G. (2010). Does habituation matter? Emotional processing theory and exposure therapy for acrophobia. Behaviour Research and Therapy, 48(11), 1139-1143. http://dx.doi.org/10.1016/j.brat. 2010.07.009.

Bandarian Balooch, S., Neumann, D. L., \& Boschen, M. J. (2012). Extinction treatment in multiple contexts attenuates $\mathrm{ABC}$ renewal in humans. Behaviour Research and Therapy, 50(10), 604-609. http://dx.doi.org/10.1016/j.brat.2012.06.003.

Barlow, D. H., \& Craske, M. G. (2007). Mastery of your anxiety and panic: Workbook (4th ed.). New York, NY: Oxford University Press.

Baum, M. (1988). Spontaneous recovery from the effects of flooding (exposure) in animals. Behaviour Research and Therapy, 26(2), 185-186. http://dx.doi.org/10.1016/ 0005-7967(88)90118-0. 
Bjork, R. A. (1994). Memory and metamemory considerations in the training of human beings. In J., \& A. P. (Eds.), Metacognition: Knowing about knowing (pp. 185-205). Cambridge, MA US: The MIT Press.

Bjork, R. A., \& Bjork, E. L. (1992). A new theory of disuse and an old theory of stimulus fluctuation. In A. F., S. M., \& R. M. (Eds.), From learning theory to connectionist theory: Essays in honor of William K. Estes (pp. 35-67). Hillsdale, NJ England: Lawrence Erlbaum Associates, Inc.

Bjork, R. A., \& Bjork, E. L. (2006). Optimizing treatment and instruction: Implications of a new theory of disuse. In L. -G., \& N. (Eds.), Memory and society: Psychological perspectives (pp. 116-140). New York, NY US: Psychology Press.

Bluett, E. J., Homan, K. J., Morrison, K. L., Levin, M. E., \& Twohig, M. P. (2014). Acceptance and commitment therapy for anxiety and OCD spectrum disorders: An empirical review. Journal of Anxiety Disorders, 28(6), 612-624. http://dx.doi.org/10.1016/j.janxdis. 2014.06.008.

Bouton, M. E. (1993). Context, time, and memory retrieval in the interference paradigms of Pavlovian learning. Psychological Bulletin, 114(1), 80-99. http://dx.doi.org/10.1037/ 0033-2909.114.1.80

Bouton, M. E. (1994). Context, ambiguity, and classical conditioning. Current Directions in Psychological Science, 3(2), 49-53. http://dx.doi.org/10.1111/1467-8721.ep10769943.

Bouton, M. E. (2002). Context, ambiguity, and unlearning: Sources of relapse after behavioral extinction. Biological Psychiatry, 52(10), 976-986. http://dx.doi.org/10.1016/ S0006-3223(02)01546-9.

Bouton, M. E., \& Brooks, D. C. (1993). Time and context effects on performance in a Pavlovian discrimination reversal. Journal of Experimental Psychology: Animal Behavior Processes, 19(2), 165-179. http://dx.doi.org/10.1037/0097-7403.19.2.165.

Bouton, M. E., \& King, D. A. (1983). Contextual control of the extinction of conditioned fear: Tests for the associative value of the context. Journal of Experimental Psychology: Animal Behavior Processes, 9(3), 248-265. http://dx.doi.org/10.1037/ 0097-7403.9.3.248.

Bouton, M. E., \& Swartzentruber, D. (1991). Sources of relapse after extinction in Pavlovian and instrumental learning. Clinical Psychology Review, 11(2), 123-140.

Cain, C. K., Blouin, A. M., \& Barad, M. (2003). Temporally massed CS presentations generate more fear extinction than spaced presentations. Journal of Experimental Psychology: Animal Behavior Processes, 29(4), 323-333. http://dx.doi.org/10.1037 0097-7403.29.4.323

Cain, C. K., Blouin, A. M., \& Barad, M. (2004). Adrenergic transmission facilitates extinction of conditional fear in mice. Learning $\mathcal{E}^{\prime}$ Memory, 11(2), 179-187. http://dx.doi.org/10. 1101/lm.71504.

Chaplin, E. W., \& Levine, B. A. (1981). The effects of total exposure duration and interrupted versus continuous exposure in flooding therapy. Behavior Therapy, 12(3), 360-368. http://dx.doi.org/10.1016/S0005-7894(81)80124-4.

Coles, M. E., Frost, R. O., Heimberg, R. G., \& Rhéaume, J. (2003). “Not just right experiences": Perfectionism, obsessive-compulsive features and general psychopathology. Behaviour Research and Therapy, 41(6), 681-700. http://dx.doi.org/10.1016/S00057967(02)00044-X

Coles, M. E., Heimberg, R. G., Frost, R. O., \& Steketee, G. (2005). Not just right experiences and obsessive-compulsive features: Experimental and self-monitoring perspectives. Behaviour Research and Therapy, 43(2), 153-167. http://dx.doi.org/10.1016/j.brat 2004.01.002.

Craske, M. G. \& Mystkowski, J. L. (2006). Exposure therapy and extinction: Clinica studies. In M. G., D., \& D. (Eds.), Fear and learning: From basic processes to clinical implications (pp. 217-233). Washington, DC US: American Psychological Association.

Craske, M. G., Kircanski, K., Zelikowsky, M., Mystkowski, J., Chowdhury, N., \& Baker, A (2008). Optimizing inhibitory learning during exposure therapy. Behaviour Research and Therapy, 46(1), 5-27. http://dx.doi.org/10.1016/j.brat.2007.10.003.

Craske, M. G., Treanor, M., Conway, C. C., Zbozinek, T., \& Vervliet, B. (2014). Maximizing exposure therapy: An inhibitory learning approach. Behaviour Research and Therapy, 58, 10-23. http://dx.doi.org/10.1016/j.brat.2014.04.006

Culver, N. C., Stoyanova, M., \& Craske, M. G. (2012). Emotional variability and sustained arousal during exposure. Journal of Behavior Therapy and Experimental Psychiatry. 43(2), 787-793. http://dx.doi.org/10.1016/j.jbtep.2011.10.009.

Culver, N. C., Vervliet, B., \& Craske, M. G. (2014). Compound extinction: Using the Rescorla-Wagner model to maximize exposure therapy effects for anxiety disorders Clinical Psychological Science, 3(3), 335-348. http://dx.doi.org/10.1177 2167702614542103

Deacon, B., Kemp, J. J., Dixon, L. J., Sy, J. T., Farrell, N. R., \& Zhang, A. R. (2013). Maximizing the efficacy of interoceptive exposure by optimizing inhibitory learning: A randomized controlled trial. Behaviour Research and Therapy, 51(9), 588-596. http://dx.doi. org/10.1016/j.brat.2013.06.006.

Eddy, K. T. Dutra, L, Bradley, R. \& Westen, D. (2004). A multidimensional meta-analysis of psychotherapy and pharmacotherapy for obsessive-compulsive disorder. Clinical Psychology Review, 24(8), 1011-1030.

Eelen, P., Hermans, D., \& Baeyens, F. (2001). Learning perspectives on anxiety disorders. In E. J. L., C., D., \& J. (Eds.), Anxiety disorders : An introduction to clinical management and research (pp. 249-264). New York: Wiley.

Eisen, J. L., Sibrava, N. J., Boisseau, C. L., Mancebo, M. C., Stout, R. L., Pinto, A., \& Rasmussen, S. A. (2013). Five-year course of obsessive-compulsive disorder: Predictors of remission and relapse. Journal of Clinical Psychiatry, 74(3), 233-239. http://dx.doi.org/10. 4088/JCP.12m07657.

Foa, E. B., \& Kozak, M. J. (1986). Emotional processing of fear: Exposure to corrective information. Psychological Bulletin, 99(1), 20-35. http://dx.doi.org/10.1037/0033 2909.99.1.20

Foa, E. B., \& McNally, R. J. (1996). Mechanisms of change in exposure therapy. In R. (Ed.), Current controversies in the anxiety disorders (pp. 329-343). New York: Guilford Press.
Foa, E. B., Grayson, J. B., Steketee, G. S., Doppelt, H. G., Turner, R. M., \& Latimer, P. R. (1983). Success and failure in the behavioral treatment of obsessive-compulsives. Journal of Consulting and Clinical Psychology, 51(2), 287-297. http://dx.doi.org/10.1037/0022006X.51.2.287

Foa, E. B., Huppert, J. D., \& Cahill, S. P. (2006). Emotional processing theory: An update. In B. O. (Ed.), Pathological anxiety: Emotional processing in etiology and treatment (pp. 3-24). New York, NY, US: Guilford Press.

Foa, E. B., Liebowitz, M. R., Kozak, M. J., Davies, S., Campeas, R., Franklin, M. E., ... Tu, X. (2005). Randomized, placebo-controlled trial of exposure and ritual prevention, clomipramine, and their combination in the treatment of obsessive-compulsive disorder. The American Journal of Psychiatry, 162(1), 151-161. http://dx.doi.org/10.1176/ appi.ajp.162.1.151.

Foa, E. B., Yadin, E., \& Lichner, T. K. (2012). Exposure and response (ritual) prevention for obsessive-compulsive disorder: Therapist guide. Oxford. New York: Oxford University Press.

Gallistel, C. R., \& Gibbon, J. (2000). Time, rate, and conditioning. Psychological Review, 107(2), 289-344. http://dx.doi.org/10.1037/0033-295X.107.2.289.

Grayson, J. B., Foa, E. B., \& Steketee, G. S. (1982). Habituation during exposure treatment: Distraction vs. attention-focusing. Behaviour Research and Therapy, 20(4), 323-328. http://dx.doi.org/10.1016/0005-7967(82)90091-2.

Groves, P. M., \& Thompson, R. F. (1970). Habituation: A dual-process theory. Psychological Review, 77(5), 419-450. http://dx.doi.org/10.1037/h0029810.

Hyman, B. M., \& Pedrick, C. (2010). The OCD workbook: Your guide to breaking free from obsessive-compulsive disorder (3rd ed.). Oakland, CA, US: New Harbinger Publications.

Jaycox, L. H., Foa, E. B., \& Morral, A. R. (1998). Influence of emotional engagement and habituation on exposure therapy for PTSD. Journal of Consulting and Clinical Psychology, 66(1), 185-192.

Kircanski, K., Mortazavi, A., Castriotta, N., Baker, A. S., Mystkowski, J. L., Yi, R., \& Craske, M. G. (2012). Challenges to the traditional exposure paradigm: Variability in exposure therapy for contamination fears. Journal of Behavior Therapy and Experimental Psychiatry, 43(2), 745-751. http://dx.doi.org/10.1016/j.jbtep.2011.10.010.

Kozak, M. J., \& Foa, E. B. (1997). Mastery of obsessive-compulsive disorder: A cognitive-behavioral approach therapist guide (1st ed.). New York, NY: Oxford University Press.

Kozak, M. J., Foa, E. B., \& Steketee, G. (1988). Process and outcome of exposure treatment with obsessive-compulsives: Psychophysiological indicators of emotional processing. Behavior Therapy, 19(2), 157-169. http://dx.doi.org/10.1016/S00057894(88)80039-X.

Lader, M. H., \& Mathews, A. M. (1968). A physiological model of phobic anxiety and desensitization. Behaviour Research and Therapy, 6(4), 411-421. http://dx.doi.org/10. 1016/0005-7967(68)90021-1.

Landauer, T. K., \& Bjork, R. A. (1978). Optimal rehearsal patterns and name learning. In M. M., P. E., \& R. N. (Eds.), Practical aspects of memory (pp. 625-632). London: Academic Press.

Lang, A. J., \& Craske, M. G. (2000). Manipulations of exposure-based therapy to reduce return of fear: A replication. Behaviour Research and Therapy, 38(1), 1-12. http://dx.doi. org/10.1016/S0005-7967(99)00031-5.

Lang, A. J., Craske, M. G., \& Bjork, R. A. (1999). Implications of a new theory of disuse for the treatment of emotional disorders. Clinical Psychology: Science and Practice, 6(1), 80-94. http://dx.doi.org/10.1093/clipsy/6.1.80.

Lang, P. J. (1971). The application of psychophysiological methods to the study of psychotherapy and behavior change. In A., \& S. L. (Eds.), Handbook of psychotherapy and behavior change: An empirical analysis (pp. 75-125). New York: Wiley.

Lovibond, P. F., Davis, N. R. \& O'Flaherty, A. S. (2000). Protection from extinction in human fear conditioning. Behaviour Research and Therapy, 38(10), 967-983. http://dx.doi. org/10.1016/S0005-7967(99)00121-7.

Mathews, A., \& Shaw, P. (1973). Emotional arousal and persuasion effects in flooding. Behaviour Research and Therapy, 11(4), 587-598. http://dx.doi.org/10.1016/00057967(73)90117-4

McKay, D., Abramowitz, J. S., Calamari, J. E., Kyrios, M., Radomsky, A., Sookman, D., ... Wilhelm, S. (2004). A critical evaluation of obsessive-compulsive disorder subtypes: Symptoms versus mechanisms. Clinical Psychology Review, 24(3), 283-313. http://dx. doi.org/10.1016/j.cpr.2004.04.003.

McSweeney, F., \& Swindell, S. (2002). Common processes may contribute to extinction and habituation. Journal of General Psychology, 129(4), 364-400. http://dx.doi.org/ 10.1080/00221300209602103

Meuret, A. E., Seidel, A., Rosenfield, B., Hofmann, S. G., \& Rosenfield, D. (2012). Does fear reactivity during exposure predict panic symptom reduction? Journal of Consulting and Clinical Psychology, 80(5), 773-785. http://dx.doi.org/10.1037/a0028032.

Meyer, J. M., Farrell, N. R., Kemp, J. J., Blakey, S. M., \& Deacon, B. J. (2014). Why do clinicians exclude anxious clients from exposure therapy? Behaviour Research and Therapy, 54, 49-53. http://dx.doi.org/10.1016/j.brat.2014.01.004.

Milad, M. R., \& Quirk, G. J. (2012). Fear extinction as a model for translational neuroscience: Ten years of progress. Annual Review of Psychology, 63, 129-151. http://dx. doi.org/10.1146/annurev.psych.121208.131631.

Milad, M. R., Rauch, S. L., Pitman, R. K., \& Quirk, G. J. (2006). Fear extinction in rats: Implications for human brain imaging and anxiety disorders. Biological Psychology, 73(1), 61-71. http://dx.doi.org/10.1016/j.biopsycho.2006.01.008.

Mueller, D., Olivera-Figueroa, L. A., Pine, D. S., \& Quirk, G. J. (2009). The effects of yohimbine and amphetamine on fear expression and extinction in rats. Psychopharmacology, 204(4), 599-606. http://dx.doi.org/10.1007/s00213-009-1491-x.

Myers, K. M., \& Davis, M. (2007). Mechanisms of fear extinction. Molecular Psychiatry, 12(2), 120-150. http://dx.doi.org/10.1038/sj.mp.4001939.

Mystkowski, J. L., Craske, M. G., \& Echiverri, A. M. (2002). Treatment context and return of fear in spider phobia. Behavior Therapy, 33(3), 399-416. http://dx.doi.org/10.1016/ S0005-7894(02)80035-1. 
Mystkowski, J. L., Mineka, S., Vernon, L. L., \& Zinbarg, R. E. (2003). Changes in caffeine states enhance return of fear in spider phobia. Journal of Consulting and Clinical Psychology, 71(2), 243-250. http://dx.doi.org/10.1037/0022-006X.71.2.243.

Norberg, M. M., Calamari, J. E., Cohen, R. J., \& Riemann, B. C. (2008). Quality of life in obsessive-compulsive disorder: An evaluation of impairment and a preliminary analysis of the ameliorating effects of treatment. Depression and Anxiety, 25(3), 248-259.

Olatunji, B. O., Davis, M. L., Powers, M. B., \& Smits, J. A. J. (2012). Cognitive-behavioral therapy for obsessive-compulsive disorder: A meta-analysis of treatment outcome and moderators. Journal of Psychiatric Research. http://dx.doi.org/10.1016/j. jpsychires.2012.08.020.

Olatunji, B. O., Wolitzky-Taylor, K. B., Willems, J., Lohr, J. M., \& Armstrong, T. (2009). Differential habituation of fear and disgust during repeated exposure to threat-relevant stimuli in contamination-based OCD: An analogue study. Journal of Anxiety Disorders, 23(1), 118-123. http://dx.doi.org/10.1016/j.janxdis.2008.04.006.

Parkinson, L., \& Rachman, S. J. (1980). Are intrusive thoughts subject to habituation? Behaviour Research and Therapy, 18(5), 409-418. http://dx.doi.org/10.1016/00057967(80)90006-6.

Pavlov, I. P. (1927). Conditioned reflexes. London: Oxford University Press.

Phelps, E. A., Delgado, M. R., Nearing, K. I., \& LeDoux, J. E. (2004). Extinction learning in humans: Role of the amygdala and vmPFC. Neuron, 43(6), 897-905. http://dx.doi. org/10.1016/j.neuron.2004.08.042.

Prenoveau, J. M., Craske, M. G., Liao, B., \& Ornitz, E. M. (2013). Human fear conditioning and extinction: Timing is everything...or is it? Biological Psychology. http://dx.doi. org/10.1016/j.biopsycho.2012.02.005.

Quirk, G. J. (2002). Memory for extinction of conditioned fear is long-lasting and persists following spontaneous recovery. Learning E Memory, 9(6), 402-407. http://dx.doi. org/10.1101/lm.49602.

Quirk, G. J., \& Mueller, D. (2008). Neural mechanisms of extinction learning and retrieval. Neuropsychopharmacology, 33(1), 56-72. http://dx.doi.org/10.1038/sj.npp.1301555.

Rabavilas, A. D., Boulougouris, J. C., \& Stefanis, C. (1976). Duration of flooding sessions in the treatment of obsessive-compulsive patients. Behaviour Research and Therapy, 14(5), 349-355. http://dx.doi.org/10.1016/0005-7967(76)90022-X.

Rachman, S. J. (1979). The return of fear. Behaviour Research and Therapy, 17(2), 164-166. http://dx.doi.org/10.1016/0005-7967(79)90028-7.

Rachman, S. J. (1989). The return of fear: Review and prospect. Clinical Psychology Review, 9(2), 147-168. http://dx.doi.org/10.1016/0272-7358(89)90025-1.

Rachman, S. J., Craske, M. G., Tallman, K., \& Solyom, C. (1986). Does escape behavior strengthen agoraphobic avoidance? A replication. Behavior Therapy, 17(4), 366-384. http://dx.doi.org/10.1016/S0005-7894(86)80069-7.

Rescorla, R. A. (1988). Pavlovian conditioning: It's not what you think it is. American Psychologist, 43(3), 151-160. http://dx.doi.org/10.1037/0003-066X.43.3.151.

Rescorla, R. A. (1996). Preservation of Pavlovian associations through extinction. The Quarterly Journal of Experimental Psychology B: Comparative and Physiological Psychology, 49B(3), 245-258.

Rescorla, R. A. (2006). Deepened extinction from compound stimulus presentation. Journal of Experimental Psychology: Animal Behavior Processes, 32(2), 135-144. http://dx.doi.org/10.1037/0097-7403.32.2.135.

Rescorla, R. A., \& Wagner, A. R. (1972). A theory of Pavlovian conditioning: Variations in the effectiveness of reinforcement and nonreinforcement. In A. H. \& W. F. (Eds.), Classical conditioning II: Current research and theory (pp. 64-99). New York: AppletonCentury-Crofts.

Rowe, M. K., \& Craske, M. G. (1998a). Effects of an expanding-spaced vs. massed exposure schedule on fear reduction and return of fear. Behaviour Research and Therapy, 36(7-8), 701-717. http://dx.doi.org/10.1016/S0005-7967(97)10016-X.

Rowe, M. K., \& Craske, M. G. (1998b). Effects of varied-stimulus exposure training on fear reduction and return of fear. Behaviour Research and Therapy, 36(7-8), 719-734.

Schmidt, R. A., \& Bjork, R. A. (1992). New conceptualizations of practice: Common principles in three paradigms suggest new concepts for training. Psychological Science, 3(4), 207-217. http://dx.doi.org/10.1111/j.1467-9280.1992.tb00029.x.
Simpson, H. B., Franklin, M. E., Cheng, J., Foa, E. B., \& Liebowitz, M. R. (2005). Standard criteria for relapse are needed in obsessive-compulsive disorder. Depression and Anxiety, 21(1), 1-8. http://dx.doi.org/10.1002/da.20052.

Stern, R., \& Marks, I. M. (1973). Brief and prolonged flooding. A comparison in agoraphobic patients. Archives of General Psychiatry, 28(2), 270-276.

Thomas, B. L., \& Ayres, J. J. B. (2004). Use of the ABA fear renewal paradigm to assess the effects of extinction with co-present fear inhibitors or excitors: Implications for theories of extinction and for treating human fears and phobias. Learning and Motivation, 35(1), 22-52. http://dx.doi.org/10.1016/S0023-9690(03)00040-7.

Tsao, J. C. I., \& Craske, M. G. (2000). Timing of treatment and return of fear: Effects of massed, uniform-, and expanding-spaced exposure schedules. Behavior Therapy, 31(3), 479-497. http://dx.doi.org/10.1016/S0005-7894(00)80026-X.

Twohig, M. P., Abramowitz, J. S., Bluett, E. J., Fabricant, L. E., Jacoby, R. J., Morrison, K. L., .. Smith, B. M. (2015). Exposure therapy for OCD from an acceptance and commitment therapy (ACT) framework. Journal of Obsessive-Compulsive and Related Disorders, 6, 167-173. http://dx.doi.org/10.1016/j.jocrd.2014.12.007.

Twohig, M. P., Hayes, S. C., Plumb, J. C., Pruitt, L. D., Collins, A. B., Hazlett-Stevens, H., \& Woidneck, M. R. (2010). A randomized clinical trial of acceptance and commitment therapy versus progressive relaxation training for obsessive-compulsive disorder. Journal of Consulting and Clinical Psychology, 78(5), 705-716. http://dx.doi.org/10. 1037/a0020508.

van Minnen, A., \& Hagenaars, M. (2002). Fear activation and habituation patterns as early process predictors of response to prolonged exposure treatment in PTSD. Journal of Traumatic Stress, 15(5), 359-367. http://dx.doi.org/10.1023/A:1020177023209.

Vansteenwegen, D., Dirikx, T., Hermans, D., Vervliet, B., \& Eelen, P. (2006). Renewal and reinstatement of fear: Evidence from human conditioning research. In M. G., D., \& D. (Eds.), Fear and learning: From basic processes to clinical implications (pp. 197-215). Washington, DC US: American Psychological Association.

Vansteenwegen, D., Hermans, D., Vervliet, B., Francken, G., Beckers, T., Baeyens, F., \& Eelen, P. (2005). Return of fear in a human differential conditioning paradigm caused by a return to the original acquistion context. Behaviour Research and Therapy, 43(3), 323-336. http://dx.doi.org/10.1016/j.brat.2004.01.001.

Vansteenwegen, D., Vervliet, B., Iberico, C., Baeyens, F., Van den Bergh, O., \& Hermans, D. (2007). The repeated confrontation with videotapes of spiders in multiple contexts attenuates renewal of fear in spider-anxious students. Behaviour Research and Therapy, 45(6), 1169-1179. http://dx.doi.org/10.1016/j.brat.2006.08.023.

Vervliet, B., Vansteenwegen, D., Baeyens, F., Hermans, D., \& Helen, P. (2005). Return of fear in a human differential conditioning paradigm caused by a stimulus change after extinction. Behaviour Research and Therapy, 43(3), 357-371. http://dx.doi.org/ 10.1016/j.brat.2004.02.005

Vervliet, B., Vansteenwegen, D., \& Eelen, P. (2004). Generalization of extinguished skin conductance responding in human fear conditioning. Learning $\mathcal{E}$ Memory, 11(5), 555-558.

Vervliet, B., Vansteenwegen, D., Hermans, D., \& Eelen, P. (2007). Concurrent excitors limit the extinction of conditioned fear in humans. Behaviour Research and Therapy, 45(2), 375-383. http://dx.doi.org/10.1016/j.brat.2006.01.009.

Wagner, A. R., \& Rescorla, R. A. (1972). Inhibition in Pavlovian conditioning: Application of a theory. In R. A., \& M. S. (Eds.), Inhibition and learning (pp. 301-336). London: Academic Press.

Watts, F. N. (1979). Habituation model of systematic desensitization. Psychological Bulletin, 86(3), 627-637. http://dx.doi.org/10.1037/0033-2909.86.3.627.

Whittal, M. L., Thordarson, D. S., \& McLean, P. D. (2005). Treatment of obsessivecompulsive disorder: Cognitive behavior therapy vs. exposure and response prevention. Behaviour Research and Therapy, 43(12), 1559-1576. http://dx.doi.org/ 10.1016/j.brat.2004.11.012.

Williams, M. T., Farris, S. G., Turkheimer, E. N., Franklin, M. E., Simpson, H. B., Liebowitz, M. \& Foa, E. B. (2014). The impact of symptom dimensions on outcome for exposure and ritual prevention therapy in obsessive-compulsive disorder. Journal of Anxiety Disorders, 28(6), 553-558. http://dx.doi.org/10.1016/j.janxdis.2014.06.001.

Wolpe, J. (1973). The practice of behavior therapy (2nd ed.). Oxford England: Pergamon. 